\title{
Estimating the Theoretical and Empirical Probability Coefficients of Oil Pipeline Transport Infrastructure Failure Modes in Nigeria's Coastal Ecosystem: Panacea for Non Optimal Deployment of Pipeline Safety and Security Management Systems
}

\author{
Theophilus Chinonyerem Nwokedi ${ }^{1 *}$ and Kenneth U. Nnadi ${ }^{1}$ \\ ${ }^{1}$ Department of Maritime Management Technology, Federal University of Technology, Owerri, \\ Nigeria.nwokeditc@gmail.com, kennethnnadi@gmail.com
}

\section{*Corresponding Author: Theophilus Chinonyerem Nwokedi}

\begin{abstract}
Failure of oil pipeline transport infrastructure in Nigeria's coastal ecosystem has continued to pose serious environmental problems with consequent economic effects. This study estimated the theoretical and empirical probabilities oil pipeline infrastructure failure modes in Nigeria. Historical research design approach was used in which time series data of 10 years on Nigeria's coastal oil pipeline infrastructure failure modes were obtained from the Nigerian National Petroleum Corporation. The statistical method of probability theory was used to determine the theoretical and empirical probabilities of oil pipeline infrastructure failure modes in order to optimally deploy pipeline safety and security management strategies. It was found that pipeline infrastructure failure by Vandalism poses the highest empirical probability and risk of occurrence.
\end{abstract}

Keywords: Probability, failure, modes, pipeline, infrastructure

\section{Introduction}

Oil pipeline infrastructure represent the systems of engineering equipment installed for purposes of drilling, storage and transportation of oil and gas resources to demand center(s) which may represent final consumption points or distributions centers for further supplies of oil and gas energy resources to varied market centers and final consumer locations. Examples of such infrastructural engineering equipment include oil storage tanks, oil well installations, offshore drilling platforms and oil pipeline transportation systems among others. This is necessarily important since the crude oil production points, processing points and sales and final consumption points are spatially distributed in different earth locations. Report by [1] indicates 
an increasing trend in Nigerian crude oil production and notes that the existence of more than 7000 kilometers of pipelines and flow lines; and 272 flow stations being operated by more than 13 oil exploration and production companies. There exists also numerous offshore oil production Platforms. These oil pipeline transport infrastructural equipment like all products of engineering are prone to failure which when it occurs imposes serious multiplier effects and impinges the operational efficiency of organizations involved; as well as the economic growth of States concerned. Thus, failure mode and effects analysis (FMEA) is usually recommended to be conducted by the Health, Safety and Environment (HSE) department on every engineering equipment and operational processes in the process industry to determine prior to commencement of use and/ or operation the likely failure modes and effects of equipment and operations to enable appropriate levels of safety and security shielding be deployed and applied to limit failures and the corresponding effects. These safety and security shields can only be optimally deployed after the empirical probabilities and risk posed by each failure mode is determined and made the basis for determination of levels of safety and security investments needed to secure the coastal pipelines.

For the purpose of this study, we define failure mode analysis of coastal pipeline infrastructure as a detailed examination and investigation of coastal pipeline infrastructural equipment in order to understand the pattern and manner in which it may collapse and fail, or is expected to collapse and/or malfunction, without successfully achieving any more the objective(s) for which it was employed [2]. Observes that the effects of oil pipeline infrastructure failure ranges from oil spill effects, loss of revenue to Government/economic effect, environmental degradation, human capital loss among others. In Nigeria for example, the Niger Delta coastal region is adjudged one of the most damaged marine ecosystem in the World. This damage is directly linked to frequent failures of oil pipeline infrastructure in the region as adequate levels of oil pipeline infrastructure safety and security shield had not been empirically determined and provided by the use of indebt Failure Mode Analysis (FMA). Studies by references [2,3] identified the basic failure modes of oil pipeline infrastructure in Nigeria to include; pipeline rupture, vandalism and fire \& explosion. While rupture is described as the sudden unanticipated collapse and/or failure of the pipeline infrastructural equipment or any part of it due to poor maintenance and/ or accidental impact on the equipment necessitated by force induced contact with the accidental object. Example is collision of floating marine crafts with 
coastal pipeline installation. The failure of oil pipeline infrastructure due to rupture is indicative of failure of the safety management practices (SMP's) and/or human error. Nigerian National Petroleum Corporation [4] annual report shows an increasing trend in oil pipeline infrastructure failure due to rupture, operational defects and maintenance challenges. According to [4], sabotage and oil theft summed up in vandalism constitute the single dominant causal mode of oil installation failures in Nigeria. Fire and explosion as a mode of failure of oil pipeline infrastructural equipment is usually occasioned by failure of the safety systems where gas pressure induced explosions leads to fire outbreaks with the attendant damages to pipeline infrastructure, oil spill effects, among other effects.

Statistics by the Nigerian National Petroleum Corporation [4] and Pipeline Products Marketing Company [5] supports the above facts that the dominant modes of oil pipeline infrastructure failure in Nigeria are rupture, vandalism and fire outbreak. Studies such as those of [6-8] analyzed oil pipeline induced and tanker accident induced oil spill in Nigeria and Europe; pointing out the need for compensation of victims, environmental remediation and proactive approach to pipeline safety and security management. The present study is intended to adopt a probability approach to measure and determine an empirical probability function to measure the risk of oil pipeline failure by each failure mode, using oil pipeline failure frequency data in order to compare the expected probability of failures by each failure mode with the observed frequencies or empirical probability function of failure mode. Comparing the probabilities of failure by the various failures modes enables decisions to be empirically made on the level of investment is shielding against future failures required for pipeline safety management systems and pipeline security management systems. The theoretical probability function/coefficient of failure modes is the value based on theoretical expectation placed on a failure mode as the level of risk of occurrence posed by that failure mode. The empirical probability function is a strong index for determining empirically, the levels of risk of occurrences posed by each failure mode and which consequently differentiates the level of deployment of safety and security resources among and between the failure modes based on their levels of risk; optimal oil pipeline safety and security shields can thus be determined.

This study therefore aims to determine the theoretical (expected) probabilities and empirical probabilities of failure modes of coastal oil pipeline infrastructure in Nigeria with a view to ensuring the optimal deployment of pipeline safety and security management systems. 
Determining the expected probability coefficients of coastal oil pipeline failures by rupture, fire explosion and vandalism in Nigeria; the empirical probability functions/coefficients of oil pipeline failures by rupture, fire and vandalism in Nigeria's coastal ecosystem, and Comparing the likelihood and/ or risk of coastal oil pipeline failure by rupture, fire and vandalism, will provide empirical support for optimal deployment of safety and security shields and management measures that will limit pipeline infrastructure failures by limiting failure per failure mode. Like failure of all engineering products, coastal oil pipeline infrastructure failure places enormous weight of waste in resources and while equally subjecting production facilities to loss of time and unplanned shutdown of production [8-10]. The effects of failure of oil pipeline infrastructure is multiple and in most cases cannot be adequately determined without conducting a multidisciplinary research involving professional and specialist in different areas of study such as environmentalists, chemists, economist, medical and health professionals, social scientists, statisticians, etc. This is because a single failure for example; a fire and explosion induced failure will exposes equipment operators at the time of the event to trauma, oil spill with the environmental effects, loss of equipment and revenue, wastage and/or loss of human capital through death and or injury, depletion of aquatic life and marine ecosystem biodiversity [11-13]. Since the focus of the present study is to analyze the failure modes of oil pipeline infrastructure with less attention on the consequence analysis, we choose for reasons of justifying the importance of this study to highlight the effects that oil pipeline failure had imposed on Nigeria. Studies by [11] note that Oil pipeline failures result to oil spill and loss oil resources with consequences of marine ecosystem and coastal environmental pollution and degradation. Oil spillage refers to the release of petroleum hydrocarbons and the related products into the environments following accidental and operational failure of oil drilling infrastructure and pipelines. The persistence of deliberate acts of sabotage and oil theft induced vandalism of coastal pipeline infrastructure also leads to oil spill. NNPC oil spill incidents report [14] indicates above $85 \%$ of oil spill in the region is caused by pipeline failures induced by acts of sabotage and oil theft. [15] notes that oil pipeline failure caused an aggregate economic loss in value of oil resources loss of N51,217,658,000.00 (fifty one billion, two hundred and seventeen million, six hundred and fifty eight thousand) naira from 1998 to 2015. Since the economic loss effects, oil spill, human capital depletion and environmental impacts afore mentioned constitute the effects and/or impacts of the uncertainty in failure of oil drilling and transportation 
infrastructure; they cannot be left unanalyzed to continue to pose high risks of losses. A top-tobottom approach to analyzing it is the use of uncertainty and/or probability approach to determine the empirical probability functions of the failure modes using the observed frequency data and comparing this with the expected probability of the failures modes enables a decision to be made based on empirical evidence on which failure mode(s) needs the highest level of safety and/ or security shielding against future failures.

\section{Data and Methods}

The study aims to determine the theoretical probability coefficients and empirical probability coefficients of oil pipeline failure modes in Nigeria's coastal ecosystem in order to empirically determine optimal deployment of safety and security management systems for coastal pipelines. The researchers obtained time series data covering a period of ten (10) years from 2006 to 2015 showing the observed frequencies and rates of oil pipeline infrastructure failure caused by each failure mode from the Nigerian National Petroleum Corporation (NNPC). The study adopted the probability theory analytical model to compute the expected probability coefficients and empirical probability coefficients of the failure modes of oil pipeline infrastructure in Nigeria, using the MATLAB software. It identified the major failure modes of oil pipeline infrastructure in Nigeria to be pipeline rupture (R), pipeline vandalism (V) and fire explosion (F). Since the failure pattern of pipeline infrastructure follow a stochastic process and the failures are assumed

to be mutually disjoint and mutually exclusive, the empirical probability function $F^{\prime}(x)=F(x) / n$ was used to determine the empirical probability for each failure mode over the 10 years period covered in the study while the probability theory which states that the probability $\mathrm{P}$ of a successful outcome $=P$ (successful outcome $)=$ number of successful outcomes/number of possible outcomes was used to determine the expected theoretical probability of occurrence of each failure mode.

\subsection{Probability Theory Explanations of Failure Modes of Oil Pipeline Infrastructure in Nigeria}

The basic concept of probability according to [16] originated in the analysis of game of chance (uncertainty) by renowned mathematicians as Blaise Pascal (1623 - 1662) and Pierre de Fermat (1601 - 1665). Probability deals with chance or uncertainty and is referred to as a random or 
stochastic process. Probability theory deals with chance or stochastic process also referred to as a random process. Since oil pipeline infrastructure failure is an incident whose occurrence is based on chance (stochastic), the modes of such failures identified earlier to include rupture, fire\&explosion and vandalism could be said to be mutually exclusive and disjoint since a single failure event cannot possible occur or be caused by the three failures modes simultaneously. Thus anticipation of uncertainty in future failure of oil pipeline infrastructure caused by the three event modes of rupture, vandalism and fire explosion can be determined using the probability theory. Probability theory states that probability of success or failure in a single trial (incident) is expressed in ratio form as:

$$
P(\text { successful outcome })=\frac{\text { number of successful outcomes }}{\text { number of possible outcomes }}
$$

It is similarly for unsuccessful outcomes. We may thus posit based (i) above that for incidents (occurrences) of oil pipeline failure; the probability that a successful oil pipeline failure occurred by rupture can be expressed as:

$$
P(R) \frac{\text { number of successluf ruptures }}{\text { number of possible outcomes }}
$$

As aforementioned, a single oil pipeline infrastructure failure incident in Nigeria presents possible failure modes (outcomes) of rupture (R), vandalism (V) and fire explosion $(\mathrm{F})$. Thus the sample space for a single incident of oil pipeline failure is represented by the set formed by the sample points as:

$$
S=\{R, V, F\}
$$

Thus the likelihood of or probability of failure by Rupture for example becomes $R=1 / 3$; and similarly for vandalism $(\mathrm{V})$ and fire explosion $(\mathrm{F})$.

The expected frequency of failure by each mode $\mathrm{F}(\mathrm{X})$ is:

$$
\begin{gathered}
F(X)=\frac{1}{3} N \\
P(R U V U F)=P(R)+P(V)+P(F) \\
P(R \cap V \cap F)=0
\end{gathered}
$$

\subsection{The Empirical Probability Function $F^{\prime}(X)$}

The frequency function $F(X)$ of a data set $X=X_{1}, X_{2}, X_{3}, \ldots, X_{n}$ generates an empirical probability measure $\mathrm{F}^{\prime}(\mathrm{X})$ defined by the equation: 


$$
F^{\prime}(X)=\frac{F(X)}{N}
$$

We call (7) the empirical probability measure [16]. The Empirical probability function measures for each oil pipeline failure mode events of rupture, vandalism, and fire explosion can be computed by using the 10 years' time series observed frequency of occurrence and employing equation (7) such that: Empirical probability coefficient for failure by rupture, vandalism and fire are given as:

$$
\begin{gathered}
F^{\prime}(R)=\frac{F(R)}{N} \\
\text { For vandalism }=F^{\prime}(V)=\frac{F(V)}{N} \\
\text { For fire \& explosion }=F^{\prime}(F)=\frac{F(F)}{N}
\end{gathered}
$$

The empirical probability coefficients of each failure mode can then be compared with expected or theoretical probability to determine appropriate levels of safety and security shields to limit failures by each oil pipeline infrastructure failure mode. Using the oil pipeline infrastructure failure incident data obtained from [4] covering a period of 10 years the study was carried out using the basic rules of probability and equations (1) to (10).

\section{Results and Discussion}

Table 1 shows that based on the probability rules, the expected/theoretical likelihood and chance of oil pipeline infrastructure failure are equal for all the three failure modes. The expected probability of oil pipeline infrastructure failure by each failure of rupture, vandalism and fire explosion is $1 / 3$. This implies the existence of fair/equal chances of failure for all the failure modes. Pipeline infrastructure management measures in Nigeria over the years has been approached through this theoretical assumption of equal chances of occurrence for all failures modes by lumping together all failure modes and applying the same degree of management measures against its occurrence without recourse to the empirical probability measures which aims to determine occurrence probabilities as a major influencing factor of management strategy

of pipeline failures. Based on the expected/theoretical probability coefficients determined on table 1 above, the expected frequency of failure by each failure mode can be estimated using equation (3). 
Table 1 The theoretical/Expected probability coefficients of Oil Pipeline Infrastructure Failure Modes. Source: authors

\begin{tabular}{ccccc}
\hline Failure mode & Rupture $=\mathrm{R}$ & Vandalism $=\mathrm{V}$ & Fire explosion $=\mathrm{F}$ & Sum \\
\hline $\begin{array}{c}\text { Theoretical or } \\
\text { expected probabilities }\end{array}$ & $1 / 3$ & $1 / 3$ & $1 / 3$ & 1 \\
\hline
\end{tabular}

The result of the expected frequency of failure by each pipeline failure mode presented on Table 2 above shows that the theoretically expected numbers of failures by the failure modes of rupture, vandalism and fire explosion is 9179.33 each. This is in agreement with the theoretical probability measure which assigns the same or fair chances of occurrence and/or failures to all failure modes. The expected frequency indicates a fair likelihood of pipeline failures by all the failures modes. This implies and/or suggests that investment in oil pipeline safety and failure control measures as well as management strategy should be equally deployed to remain on the same degree among the failures modes; since each failure mode present the same level of occurrence risk. We thus proceed to determine the empirical probability coefficients of each failure mode in each year covered in the study using (5) as shown in Table 2.

Table 2 Expected frequency of pipeline failure by each failure. Source: authors

\begin{tabular}{cccc}
\hline Failure Mode & Expected Failure Frequency & Theoretical Probability & N \\
\hline Rupture & 9179.33 & $1 / 3$ & 27538 \\
\hline Vandalism & 9179.33 & $1 / 3$ & 27538 \\
\hline Fire \& Explosion & 9179.33 & $1 / 3$ & 27538 \\
\hline
\end{tabular}

The empirical probability coefficients measure the actual risk and frequencies of failures caused by each failure mode using the observed frequencies of failure modes $F(X)$. The empirical probability function as shown in Table 3 above indicates the EPF for each failure mode in each of the years covered in the study. The EPF for rupture in the base year 2006 is 0.024 . The implication is that the probability and risk of oil pipeline failure caused by rupture in the base year is 0.024 ; which is far from certainty (ie; far from 1) and implies that pipeline failure by rupture has very minimal or less chances of occurrence in that period. Thus resources and investments for proactive management of expected rupture induced failure should be less than that of vandalism which shows higher empirical probability coefficients. Rupture as an oil 
pipeline failure mode recorded the highest empirical probability of occurrence in 2013 of 0.018 . The empirical probability of vandalism as a failure mode of oil pipeline infrastructure in the base year 2006 is 0.9871 . Vandalism maintained almost a constant empirical probability of 0.980 in each of the 10 years covered in the study.

The $F^{\prime}(V)=0.980$ for vandalism is very close to 1 , indicating that Vandalism dominated oil pipeline infrastructure failures incidents in each of the years covered in the study. Thus to optimize investment in pipeline safety and security, higher degree of investment in safety and security will be made in controlling vandalism than rupture and fire explosion. Similarly, the empirical probability for oil pipeline failure by fire \& explosion in the base year is 0.011 with an EPF of zero (0) in the year 2010. The policy implications for maritime safety and coastal security management agencies such as the Nigerian maritime administration and safety agency (NIMASA), the NNPC and the Pipeline Product Marketing Company (PPMC) is that vandalism poses highest risk of pipeline failure modes. Moreover, since vandalism is observed to be caused by security gaps and challenges, much investment should go into the security management of coastal pipeline infrastructure especially in closing legitimacy gaps. Table 3 below gives the empirical probability function of each oil pipeline failure mode determined by aggregating the observed frequency of failure by each mode over the 10 years covered in the study.

Table 3 Empirical probability of function for each oil pipeline failure mode from 2006 - 2015.

Source: authors

\begin{tabular}{lllllllllll}
\hline Year & $\mathbf{2 0 0 6}$ & $\mathbf{2 0 0 7}$ & $\mathbf{2 0 0 8}$ & $\mathbf{2 0 0 9}$ & $\mathbf{2 0 1 0}$ & $\mathbf{2 0 1 1}$ & $\mathbf{2 0 1 2}$ & $\mathbf{2 0 1 3}$ & $\mathbf{2 0 1 4}$ & $\mathbf{2 0 1 5}$ \\
\hline $\mathbf{F}^{\prime}(\mathbf{R})$ & 0.0024 & 0.0061 & 0.0141 & 0.0182 & 0.0271 & 0.0068 & 0.0114 & 0.018 & 0.0085 & 0.0172 \\
\hline $\mathbf{F}^{\prime}(\mathbf{V})$ & 0.9871 & 0.9884 & 0.9752 & 0.9791 & 0.9721 & 0.9844 & 0.9738 & 0.9725 & 0.983 & 0.9741 \\
\hline $\mathbf{F}^{\prime}(\mathbf{F})$ & 0.011 & 0.0055 & 0.0107 & 0.0027 & 0 & 0.0089 & 0.0141 & 0.0094 & 0.0085 & 0.0087 \\
\hline
\end{tabular}

The result on Table 4 indicates that the aggregate empirical probability coefficients for each of the failure modes over the period covered in the study to $0.0110,0.9804$ and 0.0086 for rupture, vandalism and fire explosion respectively. This supports the earlier findings that vandalism dominates oil pipeline infrastructure failures modes in Nigeria as it has the highest empirical probability of occurrence. The number of total oil pipeline infrastructure failures by 
vandalism, rupture and fire explosion over the period between 2006 and 2015 based on the result of the analysis is 26,997.99 (twenty six thousand nine hundred and ninety seven), 304.00 (three hundred and four) and 236.00 (two hundred and thirty six) failures respectively. This amounts to $98.04 \%$ failures by vandalism, $1.10 \%$ failures by rupture and 0.86 failures by fire explosion. Thus oil pipeline security management measures should be employed more to curb sabotage and oil theft induced pipeline vandalism. While pipeline safety majors should be targeted on rupture and fire explosion.

Table 4 Empirical probability functions (EPF) aggregated over the period of 10 years covered in the study. Source: authors

\begin{tabular}{llll}
\hline Failure Mode & $\begin{array}{l}\text { Empirical probability } \\
\text { coefficients }\end{array}$ & $\begin{array}{l}\text { No. of Failure by each Failure } \\
\text { Mode }\end{array}$ & $\%$ \\
\hline Rupture & 0.0110 & 304.00 & $1.1 \%$ \\
\hline Vandalism & 0.9804 & 26997.99 & 98.04 \\
\hline Fire\& explosion & 0.0086 & 236.00 & 0.86 \\
\hline
\end{tabular}

The result on Table 5 indicates that the aggregate empirical probability coefficients for each of the failure modes over the period covered in the study to $0.0110,0.9804$ and 0.0086 for rupture, vandalism and fire explosion respectively. This supports the earlier findings that vandalism dominates oil pipeline infrastructure failures modes in Nigeria as it has the highest empirical probability of occurrence. The number of total oil pipeline infrastructure failures by vandalism, rupture and fire explosion over the period between 2006 and 2015 based on the result of the analysis is 26,997.99 (twenty six thousand nine hundred and ninety seven), 304.00 (three hundred and four) and 236.00 (two hundred and thirty six) failures respectively. This amounts to $98.04 \%$ failures by vandalism, $1.10 \%$ failures by rupture and 0.86 failures by fire explosion. Thus oil pipeline security management measures should be employed more to curb sabotage and oil theft induced pipeline vandalism. While pipeline safety majors should be targeted on rupture and fire explosion.

Comparing the theoretical probabilities of failures with the Empirical probabilities of failure for each failure mode reveals differences. The theoretical probabilities for rupture and fire explosions are higher with equally higher expected frequencies of failure than their respective 
empirical failure rates. For example, the expected frequencies of failure for rupture and fire explosion is higher than the actual frequencies by 8875.33 and 8943 respectively.

Table 5 Comparison of empirical probability functions with expected frequencies of failures.

Source: authors

\begin{tabular}{llllll}
\hline $\begin{array}{l}\text { Failure } \\
\text { Mode }\end{array}$ & $\begin{array}{l}\text { Theoretical } \\
\text { Probability }\end{array}$ & $\begin{array}{l}\text { Expected } \\
\text { Frequency } \\
\text { of Failure }\end{array}$ & $\begin{array}{l}\text { Empirical } \\
\text { probability }\end{array}$ & $\begin{array}{l}\text { Actual Frequency } \\
\text { of Failure over the } \\
\text { period. }\end{array}$ & Difference \\
\hline Rupture & 0.3333 & 9179.33 & 0.0110 & 304.00 & -8875.33 \\
\hline Vandalism & 0.3333 & 9179.33 & 0.9804 & 26997.99 & 17818.66 \\
\hline $\begin{array}{l}\text { Fire \& } \\
\text { Explosion }\end{array}$ & 0.3333 & 9179.33 & 0.0086 & 236.00 & -8943 \\
\hline
\end{tabular}

This implies that the theoretical probability of failure and the expected frequency of failure if based upon for pipeline safety and security decisions will lead to over investment in rupture and fire explosion control measures which will amount to waste of the excess investment safety at the short run. The theoretical probability approach and the expected frequency of failure measure equally underestimated the actual frequency of failure by vandalism by 17818.66 . The implications of this for decision purposes is that investment in oil pipeline security management measures to limit vandalism if based on theoretical probability and expected frequency of failure will be under estimated to the detriment of the economy. The empirical probability measure and the corresponding actual frequency of failure remain the best safety and security investment decision approach for oil pipeline infrastructure failure control using the probability theory approach.

\section{Conclusion}

Pipeline vandalism induced by security gaps and challenges remain the single most dominant mode of oil pipeline infrastructure failure in Nigeria. With empirical probability functions of $0.0110,0.9804$ and $0-0086$ for rupture, vandalism and fire explosion respectively; it is certain that vandalism as a mode of oil pipeline failure puts the greatest risk of occurrence on the Nigerian coastal oil pipeline infrastructure having caused about $98.04 \%$ of all oil pipeline failures over the period covered in the study. This is followed by oil pipeline rupture which had an occurrence rate of $1.10 \%$ and fire \& explosion with occurrence rate of $0.86 \%$. Investment in coastal pipeline infrastructure safety and security measures should concentrate more on coastal 
pipeline infrastructure security to curb vandalism. This may be achieved by closing security gaps.

\section{Acknowledgements}

I sincerely acknowledge the support of the Department of maritime management Technology, Federal University of Technology, Owerri and the Nigeria national Petroleum Corporation (NNPC).

\section{References}

[1] Nwokedi, T.C., Okoroji, L.I., Nze, I.C. \& Ndukwu, I.P. (2015). Oil Exploration and production waste management practices: comparative analysis for reductive in hazardous E\&P waste generation in offshore oil platforms in Nigeria. Journal of environment and earth science. 5(4), 101-110.

[2] Onuoha, F.C. (2008). Oil pipelines sabotage in Nigeria: Dimensions, actors and implications for national security. African Security Review, Institute for Security Studies. $17(3), 42-50$.

[3] Ademuwagun, O. (2017). Risk Analysis of oil spillage in the Niger Delta marine environment. An unpublished bachelor thesis, Federal University of Technology Owerri.

[4] NNPC. (2016). Nigeria National Petroleum Corporation Annual Statistical Bulletin. $\begin{array}{llll}\text { Retrieved } \quad \text { 13th } & \text { June, } & \text { from }\end{array}$ http://www.nnpcgroup.com/PublicRelations/OilandGasStatistics/AnnualStatisficsBuletin.a spx.

[5] PPMC. (2008). Pipeline products marketing company annual statistical report 2008 edition.

[6] Adati, A. K. (2012). Oil exploration and spillage in the Niger Delta of Nigeria. Journal of Civil and Environmental Research. 2(3), 38-52.

[7] Adelana, S.O., Adeosun, T.A., Adesina, A. O. \& Ojuronye, M. O. (2011). Environmental pollution and remediation: Challenges and Management of Oil Spill in Nigeria Coastal Areas. American Journal of Science and Industrial Research. 10.5251(836), 834-845. 
[8] Micheal, F. \& Hui, W. (2015). Compensating victims of a European deepwater horizon accident: OPOL revisited. Marine policy. 6, 25-36.

[9] ArbenMullai and Ulf Paulson. (2011). A grounded Theory Model for analysis of Marine Accidents. Accident Analysis and Prevention Journal. 43, 1590-1603.

[10] Aluko, M.O. (2004). Sustainable development, environmental degradadtion and entrenchment of poverty in the Niger Delta of Nigeria. Kalma-Raj Journal of Human Ecology. 15(1), 13-20.

[11] ABS. (2014). Risk Assessment Applications for the Marine and Offshore Oil and Gas Industries; Houston. American Bureau of Shipping.

[12] Nwokedi, T.C., Ibe, C.C., Ntor-ue M. \& Onyemechi C. (2017). Economic Implications of Marine Oil Spill to Nigeria: A Case for Improvement in Coastal Pipeline Management and Surveillance Practices. International Journal of Economy, Energy and Environment. 2(3), 40-47.

[13] The United Nations Convention on Law of the Seas (UNCLOS, 1982). United Nations, London.

[14] Nwokejiegbe, C. E. (2014). An assessment of the impacts of marine pollution by oil spill in Nigeria. B. Tech. Thesis in the Department of Maritime Management Technology, Federal University of Technology, Owerri.

[15] Omofomwan, S.I. \& Odia, L.O. (2009). Oil Exploitation and Conflict in the Niger Delta Region of Nigeria. Journal of Human Ecology. 26(1), 25-30.

[16] Rosenkrantz, W.A. (2009). Introduction to probability and statistics for science, engineering and finance. Chapman and Hall, London. 